\title{
Mosaico da linguagem das crianças bilíngues bimodais: estudos experimentais ${ }^{1}$ \\ Language mosaic in bimodal bilingual children: experimental studies
}

Ronice Müller de Quadros*

Universidade Federa de Santa Catarina

Florianópolis - Santa Catarina / Brasil

Aline Lemos Pizzio**

Universidade Federa de Santa Catarina

Florianópolis - Santa Catarina / Brasil

Carina Rebello Cruz ${ }^{* * *}$

Universidade Federa de Santa Catarina

Florianópolis - Santa Catarina / Brasil

Aline Nunes de Sousa****

Universidade Federa de Santa Catarina

Florianópolis - Santa Catarina / Brasil

RESUMO: O presente trabalho apresenta a metodologia utilizada no estudo experimental que investiga o desenvolvimento bilíngue bimodal de crianças surdas com implante coclear (IC) e crianças ouvintes filhas de pais surdos (Kodas) $)^{2}$, com faixa etária entre 4 e 8 anos. Além desses dois grupos de crianças, participaram da pesquisa crianças surdas filhas de pais surdos ou filhas de pais ouvintes, e adultos ouvintes filhos de pais surdos, com o intuito de constituírem os grupos de controle. Inicialmente, descrevemos o estudo experimental

\footnotetext{
*ronice.quadros@ufsc.br

** alinepizzio@cce.ufsc.br

*** crcpesquisa@gmail.com

**** aline.fortaleza.ce@gmail.com

${ }^{1}$ Estudo apresentado no XVII Congresso Internacional de Linguística e Filologia da América Latina (ALFAL) na cidade de João Pessoa (Paraíba, Brasil), em julho de 2014.

${ }^{2}$ Kodas: Kids of deaf adults.
} 
desenvolvido e apresentamos como organizamos as feiras para coleta de dados. E, em seguida, apresentamos os testes utilizados no estudo, que contemplam os aspectos linguísticos da Língua de Sinais Brasileira (Libras) e do Português Brasileiro (PB) e formam o mosaico da linguagem dessas crianças. Concluímos com os resultados gerais das investigações realizadas até o momento.

PALAVRAS-CHAVE: Aquisição da linguagem; Avaliação da linguagem; Bilinguismo Bimodal; Crianças ouvintes; Crianças surdas; Implante coclear.

\begin{abstract}
This article considers the method used in an experimental study investigating the bilingual, bimodal development of deaf children with cochlear implants (CI) and hearing children with deaf parents (Kodas), aged between four and eight years old. In addition to these two groups of children, deaf children of deaf parents or hearing parents, and hearing adults who had deaf parents, participated as control groups. Initially, we describe our experimental study and explain how we organized the data-collection fairs. Next, we outline the tests we used in the study, which consider the linguistic aspects of Brazilian Sign Language (Libras) and Brazilian Portuguese (BP) and make up the linguistic mosaic of these children. We conclude with some comments on our preliminary results drawn from the data so far.
\end{abstract}

KEYWORDS: Language acquisition; Language assessment, Bimodal bilingualism; Hearing children; Deaf children; Cochlear implant.

\title{
Introdução
}

Os estudos sobre aquisição bilíngue bimodal por meio de estudos longitudinais e experimentais ainda são recentes (EMMOREY et al. 2008; CHEN-PICHLER et al. 2010; LILLO-MARTIN et al. 2010; QUADROS et al. 2010; TOOHEY 2010; DAVIDSON et al. 2013; QUADROS et al. 2012; CRUZ et al. 2014). As investigaçōes podem ser conduzidas com diferentes focos, como: (1) analisando como ocorre o processo de aquisição em si, por meio da comparação do desempenho das crianças bilíngues bimodais (Kodas) com o de crianças monolíngues, (2) analisando se os processos de aquisição bilíngue unimodal e bimodal são semelhantes ou não, e se os efeitos decorrentes da modalidade visuoespacial são observados no decorrer do processo de aquisição da linguagem.

Estamos desenvolvendo estudos sobre aquisição bilíngue bimodal por crianças Kodas e por crianças surdas com implante coclear (IC) que possuem acesso irrestrito ou restrito à língua de sinais, e que receberam e ativaram o IC precocemente (entre 2 e 4 anos de idade). As crianças surdas com IC, filhas de pais surdos, possuem acesso irrestrito à língua de sinais, enquanto 
que, as crianças surdas com IC, filhas de pais ouvintes, possuem um acesso restrito à língua de sinais (a exposição à língua de sinais geralmente é menor, pois os pais estão iniciando a aprendizagem da língua de sinais, e a criança interage com usuários da língua de sinais em outros contextos fora do lar). Dessa forma, para essas crianças o processo de aquisição da linguagem ocorre desde o nascimento ou muito cedo, por meio da língua de sinais e o atraso no início do processo de aquisição da linguagem é evitado. Nesses casos, a criança surda tem a oportunidade de desenvolver-se linguisticamente de forma esperada (normal), pois entre o período de diagnóstico da perda auditiva e realização da cirurgia para colocação do IC, ativação do mesmo, mapeamento (regulagens) e 'real acesso' à língua oral a criança tem acesso à língua de sinais por meio de interaçôes com nativos ou não-nativos fluentes.

Atualmente, a maioria das crianças surdas com IC não tem a oportunidade de adquirir a língua de sinais desde o nascimento ou ainda na infância. Além disso, por um período também não têm acesso à língua oral, pois o 'real acesso' aos sons inicia somente após meses ou anos após o nascimento, quando a cirurgia para colocação do IC é realizada e o mesmo é ativado. Resultados de pesquisas mostram que mesmo com exposição exclusiva à língua oral e acompanhamento terapêutico, por longo período de uso do IC, muitas crianças surdas com IC não alcançam o desenvolvimento linguístico na língua oral quando comparadas com crianças ouvintes com a mesma faixa etária (FORTUNATO, et al. 2009; STUCHI et al. 2007; PADOVANI e TEIXEIRA, 2005; GEERS, 2004).

A oportunidade linguística de crianças surdas com IC iniciarem o processo de aquisição da linguagem na língua de sinais e somarem a esse processo a aquisição de uma língua de modalidade oral, quando recebem precocemente o IC, é investigada em nosso estudo experimental. Além disso, investigamos como as crianças Kodas estão adquirindo a linguagem por meio de duas línguas de diferentes modalidades e, a partir dos resultados, comparamos e analisamos as semelhanças e as diferenças no processo de aquisição da linguagem bilíngue bimodal por crianças surdas com IC e Kodas. A descrição do estudo, assim como, dos testes utilizados e resultados obtidos até o momento serão apresentados a seguir.

\section{Descrição do estudo experimental}

O estudo experimental descrito a seguir, tem como principal objetivo investigar o desenvolvimento bilíngue bimodal de crianças surdas com 
IC e crianças ouvintes filhas de pais surdos (Kodas). Esse estudo faz parte do Projeto 'Desenvolvimento Bilíngue Bimodal'3, desenvolvido pelas pesquisadoras: Dra Diane Lillo-Martin (University of Connecticut), Dra Ronice Quadros (Universidade Federal de Santa Catarina) e Dra Deborah Chen Pichler (Gallaudet University), no Brasil e nos Estados Unidos, entre 2010 e $2014^{4}$.

Nesse estudo as crianças brasileiras foram avaliadas na Língua de Sinais Brasileira (Libras) e em Português Brasileiro (PB), e as crianças americanas na Língua de Sinais Americana (ASL) ${ }^{5}$ e em Inglês, em testes equivalentes nos dois pares de línguas indicados para a faixa etária que investigamos (4-8 anos). Para cada aspecto linguístico avaliado, primeiramente foram selecionados testes validados em cada uma das línguas e posteriormente comparados. Os testes com formato idêntico ou muito semelhante formaram um subconjunto de testes nos dois pares de línguas: Libras- PB e ASL- Inglês. No entanto, quando não foram encontrados testes idênticos ou semelhantes nos dois pares de línguas, a equipe envolvida no Projeto traduziu, adaptou e/ou elaborou testes para avaliação de aspectos linguísticos.

Com relação às adaptaçôes, destacamos o desafio quanto às mudanças necessárias no formato e aplicação de alguns testes inicialmente desenvolvidos para falantes de uma língua oral. Nesses testes há a possibilidade de uma imagem ser visualizada ao mesmo tempo em que uma instrução/informação oral é dada. Em testes em línguas de sinais, isso não é possível, pelo fato de os estímulos visuais serem recebidos pelo mesmo canal de recepção da língua. Dessa forma, modificações no formato de testes foram realizadas para que atenção compartilhada entre os estímulos e as informações fornecidas na língua de sinais ocorresse de forma adequada.

O grupo de examinadores (aplicadores dos testes) foi formado por surdos e ouvintes bilíngues bimodais, preparados para a aplicação de cada teste. Os examinadores surdos aplicaram os testes em Libras, e os examinadores ouvintes, os testes em $\mathrm{PB}$. A preparação do grupo de

\footnotetext{
${ }^{3}$ Informações sobre o projeto 'Desenvolvimento Bilíngue Bimodal' em http://bibibi. uconn.edu/.

${ }^{4}$ Esse estudo conta com recursos do National Institute of Health - NIDCD Recurso \#DC00183 e NIDCD grant \#DC009263; e do Conselho Nacional de Pesquisa (CNPq) - Recurso \#CNPQ \#200031/2009-0 e \#470111/2007-0.
}

${ }^{5}$ ASL: American Sign Language 
examinadores antes das feiras foi fundamental para que as aplicações ocorressem conforme os requisitos de cada teste de uma forma que motivasse a criança a participar de testes com diferentes níveis de complexidade e extensão. Inclusive, uma das estratégias para motivação da criança para participar de todos os testes foi a realização de um "bingo". Cada criança recebeu uma cartela com espaços em branco na qual deveriam ser coladas fichas com desenhos de animais. A cada teste realizado, a criança recebia uma ficha. As crianças acharam divertida a brincadeira, pois compartilhavam entre os colegas as suas 'conquistas'.

Em relação à coleta de dados, a aplicação de todos os testes foi filmada para posterior análise. O registro dos dados recebeu atenção especial em nosso estudo, pois durante a aplicação de alguns testes o posicionamento da filmadora deveria estar voltado para a criança e, em outros para a criança e o material que estava sendo utilizado (fichas, brinquedos, tela do computador) e/ou também para o examinador, possibilitando a transcrição adequada dos dados (respostas).

A coleta de dados ocorreu em feiras realizadas em diferentes cidades do Brasil e dos Estados Unidos, onde foram aplicados 24 testes, sendo a metade deles em Libras e a outra metade em PB. As feiras reuniram os pais e as crianças com atividades lúdicas, pedagógicas e sociais que tornaram os dias de coleta um momento prazeroso. Além dos testes, os pais e/ou cuidadores preencheram um questionário sobre o desenvolvimento geral da criança e autorizaram a participação da criança no presente estudo por meio da assinatura do Termo de Consentimento Livre e Esclarecido.

\section{Apresentação dos testes}

Nesta seção, apresentamos os testes em Libras e em PB utilizados para o estudo experimental desenvolvido, citando cada teste e os respectivos autores, o objetivo principal e algumas informaçóes sobre o material e a aplicação.

Conforme citado na primeira seção, os testes são equivalentes em Libras e PB e podem se diferenciar ou não em relação ao formato. Assim, distribuímos os testes em duas seções: na Seção 2.1 estão os testes com formatos diferentes, ou seja, têm os mesmos objetivos, mas não seguem os mesmos procedimentos para a aplicação, e na Seção 2.2 estão os testes com mesmo formato que além de mesmos objetivos seguem os mesmos procedimentos para aplicação, podendo ter inclusive a mesma quantidade 
de itens de avaliação. Além disso, apresentamos os protocolos de avaliação da linguagem (preenchidos pelos pais), a forma de avaliação da interação entre pais-filho e o teste de Quociente de Inteligência (QI) utilizado.

\subsection{Testes com mesmos objetivos e diferentes procedimentos para aplicação (formatos diferentes)}

\begin{tabular}{|c|c|}
\hline Libras & PB \\
\hline $\begin{array}{l}\text { O teste de habilidades linguísticas em Libras } \\
\text { foi adaptado a partir do teste existente para } \\
\text { a ASL da Northren Signs Research Inc: } \\
\text { Assessing ASL Development Receptive } \\
\text { Skills Test. É um teste organizado em um } \\
\text { DVD. Antes de iniciá-lo o experimentador, } \\
\text { no próprio DVD, explica o teste e convida } \\
\text { a criança a fazer uma demonstração com } \\
\text { três itens. Os itens são compostos de } \\
\text { sentenças que são sinalizadas, e a criança } \\
\text { precisa escolher uma figura que melhor } \\
\text { representa o que foi dito em sinais, entre } \\
\text { quatro figuras. São } 40 \text { itens que incluem } \\
\text { distribuição/número; negação; nome- } \\
\text { verbo; verbos espaciais/locação; verbos } \\
\text { espaciais/ação; classificadores de tamanho } \\
\text { e forma; classificadores manuais; mudança } \\
\text { de papéis e condicionais. }\end{array}$ & $\begin{array}{l}\text { Avalia o desenvolvimento da linguagem em } \\
\text { português (inclui habilidades comunicativas } \\
\text { e linguísticas). Este teste a presenta } \\
\text { diferentes níveis etários de aplicação e avalia } \\
\text { tanto a compreensão quanto a produção } \\
\text { linguística. As áreas contempladas vão } \\
\text { desde a fonologia, a morfologia e a sintaxe à } \\
\text { semântica e pragmática. O experimentador } \\
\text { faz a intervenção proposta para cada nível e } \\
\text { registra as respostas da criança em uma ficha } \\
\text { específica. O experimentador passa para o } \\
\text { nível seguinte quando a criança consegue } \\
\text { responder as atividades previstas no nível } \\
\text { anterior. }\end{array}$ \\
\hline
\end{tabular}




\section{Morfologia Verbal}

(Adaptado pela Equipe do Projeto Desenvolvimento Bilíngue Bimodal)

Este teste avalia a capacidade da criança em julgar o que está certo ou errado quanto à concordância verbal usada para representar um determinado fato. O teste utiliza a metodologia do teste Truth Value Judgment Task - TVJT (CRAIN \& MCKEE, 1986; CRAIN \& THORNTON, 1998), sendo que o material foi adaptado para línguas de sinais. Assim, no teste adaptado não são utilizados fantoches, mas vídeos e com um experimentador que está vestido de gato. $\mathrm{O}$ gato (experimentador) avisa à criança que nem sempre consegue prestar muita atenção nas coisas e pede para a criança assistir um vídeo com uma dramatização. Esta dramatização representa o verbo que deverá ter a concordância verbal representada por meio dos personagens (gato, porco e coelho) que poderão ocupar a posição de sujeito ou objeto. Posteriormente, a criança assiste a um novo vídeo com o experimentador vestido de gato sinalizando a ação em Libras e julgará se o gato usou a concordância do verbo correta para representar o vídeo estímulo. $\mathrm{O}$ vídeo do teste é produzido com personagens presentes e, posteriormente, sem os personagens presentes. Há dois itens de demonstração (exemplos), e o teste está dividido em duas partes com 16 itens para serem julgados em cada uma. Todo o teste foi produzido em Libras e filmado com um experimentador usuário nativo da Libras. $\mathrm{O}$ experimentador presente registra as respostas da criança em formulário próprio.

\section{Morfologia Verbal}

(Equipe do Projeto Desenvolvimento Bilíngue Bimodal)

Este é um teste para eliciar a produção da criança quanto à concordância verbal marcada nos verbos (auxiliar ou principal). A marcação que está sendo eliciada é de número (plural e singular, somente com terceira pessoa). Este teste conta com um experimentador que irá interagir com a criança. A criança recebe uma ficha que possui um conjunto de quatro figuras, sendo que uma das figuras estará marcada. O experimentador 2 , com orelhas de um animal, terá o mesmo conjunto de 4 figuras, sem a figura marcada. À criança é solicitado que descreva a figura marcada de tal forma que possibilite ao experimentador 2 escolher, em sua ficha, a figura que melhor representa a descrição feita pela criança. Após a descrição, a criança confirma se o experimentador 2 escolheu a figura certa. Há um item de demonstração e 10 de avaliação. 
5. Teste de consciência fonológica na Libras (CRUZ, 2008)

Este instrumento, proposto por Cruz e Lamprecht (CRUZ, 2008), avalia a consciência fonológica com base no parâmetro de configuração de mão (CM). Primeiramente, é avaliado se a criança conhece o vocabulário e reconhece as figuras que serão utilizadas no teste de consciência fonológica (48 imagens). Caso a criança não reconheça a figura e/ou não tenha adquirido o item lexical na Libras, é possível intervenção do examinador para que a criança adquira o conceito e o relacione à figura. As crianças que denominam adequadamente todas as figuras realizam o teste de consciência fonológica. Cada tarefa consiste em visualizar quatro imagens/ figuras (um alvo e três opções de resposta) e selecionar entre as opções de resposta aquela que possui a mesma configuração de mão do alvo, quando sinalizadas em Libras. Há 12 itens de avaliação - sendo que estes estão divididos em 4 grupos conforme a formação dos sinais - e 4 itens de prática.
6. Perfil de habilidades fonológicas (ALVAREZ, CARVALHO E CAETANO, 2004)

É constituído pelos itens que identificam e compóem as habilidades fonológicas (análise, adição, segmentação, subtração, substituição, rimas, rima sequencial, reversão silábica e imagem articulatória). O PHF foi desenvolvido para a aplicação em crianças entre 5 e 10 anos. Há tarefas específicas para crianças a partir de 7 anos. Conforme a faixa etária o desempenho é avaliado como: 'sob-atenção' e 'esperado'. 
7. Teste de pseudossinais

(Equipe do Projeto Desenvolvimento Bilíngue Bimodal)

Este teste avalia a memória fonológica das crianças utilizando sinais sem sentido que apresentam padrôes fonológicos que fazem parte da Libras. O teste de pseudossinais da Libras foi desenvolvido observando-se a estrutura interna dos sinais, conforme segue: (a) sinais com uma mão e uma configuração de mão, com e sem movimento direcional; (b) sinais com uma mão e duas configuraçôes de mão, com e sem movimento direcional; (c) sinais com duas mãos e uma configuração de mão, com movimentos simétricos e assimétricos; (d) sinais com duas mãos e duas configuraçōes de mão, com movimentos simétricos e assimétricos; (e) sinais com duas mãos e duas configurações de mão envolvendo uma mão passiva (morfema preso); (f) sinais com duas mãos e uma configuração de mão com movimento direcional e (g) sinais com duas mãos, duas configuraçôes de mão e duas locações. Cada uma destas categorias conta com três itens, formando um conjunto de 33 sinais para avaliação. Há três itens de demonstração (três pseudossinais). Neste teste a criança assiste à produção de cada pseudossinal por meio de um vídeo, apresentado em um computador e, em seguida repete o sinal visualizado. Assim como é realizado no teste de pseudopalavras, neste teste cada item é registrado com 0 (zero) se o experimentador julgar que a produção da criança não corresponde aos itens sublexicais do pseudossinal alvo em um ou mais itens sublexicais e 1 (um) se a repetição for considerada adequada. As respostas incorretas são registradas no protocolo pelo experimentador com anotaçôes específicas.
8. Teste de repetição de pseudopalavras para crianças brasileiras (SANTOS \& BUENO, 2003)

Este teste avalia a memória fonológica das crianças utilizando 40 palavras sem sentido, que apresentam padrões fonológicos que fazem parte do $\mathrm{PB}$. Há palavras com alta, média e baixa semelhança com o PB. Elas são faladas pelo próprio experimentador que esconde os lábios (com a ficha utilizada para leitura das pseudopalavras) evitando dessa forma a leitura orofacial. Cada item é registrado com 0 (zero) se o experimentador julgar que a produção da criança não corresponde ao som da palavra apresentada diferindo da pseudopalavra alvo em um ou mais fonemas e 1 (um) se a repetição for considerada adequada. As respostas incorretas são registradas no protocolo pelo experimentador com anotações específicas. 
9. Instrumento de Avaliação da Língua de Sinais - IALS (QUADROS \& CRUZ,)

No IALS a criança assiste a um desenho animado do 'Tom \& Jerry' com duração de 1'10", duas vezes. Após narra o que assistiu a alguém fluente em Libras.
O teste (9) foi realizado apenas em Libras, pois faz parte de um Instrumento de Língua de Sinais que foi considerado importante ser incluído na bateria de testes. Não foi considerado necessário realizar um teste similar em Português, pois o PSL apresentado no item 2 inclui os aspectos analisados.

\title{
2.2 Testes com mesmos objetivos e mesmos procedimentos para aplicação (mesmo formato)
}

\author{
10. Teste da ordem dos sinais \\ 11. Teste da ordem das palavras
}

(Equipe do Projeto Desenvolvimento Bilíngue Bimodal)

Avalia se a criança produz a ordenação do nome-adjetivo correta das palavras/sinais em uma frase. Para este teste, há dois experimentadores. Um conduz o teste e o outro faz o teste com a criança (usa orelhas de um animal para tornar o teste mais interessante e motivar a criança a conversar com o adulto). A criança recebe uma ficha com dois quadros com imagens que representam opostos. Inicialmente é solicitado que a criança visualize cada quadro, observe as diferenças entre as figuras dos dois quadros e que descreva ao experimentador o que visualiza em um dos quadros com a borda colorida. É solicitada a descrição da imagem com borda em vermelho para avaliação em Libras e em amarelo para avaliação em PB. O segundo experimentador tem as fichas sem marcação para que reconheça a descrição que a criança faz. O experimentador anota as sentenças produzidas pela criança, além da sessão ser filmada para posterior verificação. $\mathrm{O}$ teste consta de 2 itens de demonstração e 10 de avaliação. 
(WILLIAMS, 1997)

O EVT é um teste para avaliação do vocabulário. O teste apresenta um conjunto de fichas com ilustrações e fichas de avaliação por faixa etária. O experimentador apresenta a ficha e pede para a criança identificá-la por meio de uma palavra/sinal. Em um segundo momento, no caso do teste em português, o experimentador diz o nome da figura e a criança deve oferecer um sinônimo. Em Libras, há apenas a nomeação das figuras do início ao fim do teste. Este teste foi desenvolvido para avaliar crianças americanas e, por isso, além da tradução para o PB e para Libras as fichas foram adaptadas a cada contexto social e linguístico referente a cada língua.

\section{ABFW}

\section{(ANDRADE, BEFI-LOPES, FERNANDES e WERTZENER, 2004)}

Para a avaliação fonológica em PB utilizamos a prova de nomeação. Nessa prova o examinador solicita à criança que denomine cada figura apresentada. Quando a criança não reconhece a figura ou a denomina de forma não esperada o examinador a denomina e solicita à criança novamente a denominação após apresentação de outras 5 figuras. Este teste é composto por 34 figuras. As respostas são transcritas foneticamente na ficha de acompanhamento do teste. Quando a criança apresenta desvios fonológicos, é realizada a prova de imitação, visando investigar se a criança não produziu os fonemas na avaliação anterior por alguma dificuldade articulatória (nível fonético). O teste de imitação é composto por 39 vocábulos que devem ser repetidos pela criança. As respostas são transcritas foneticamente na ficha de acompanhamento do teste.

\section{Avaliação Fonológica na Libras, teste adaptado}

(CRUZ, 2008)

Para avaliação fonológica na Libras foi utilizada a nomeação de figuras do teste de consciência fonológica, composta por 48 vocábulos, com a mesma instrução do ABFW (prova de nomeação). 


\section{Teste de figuras para Discriminação Fonêmica - TFDF}

(SANTOS-CARVALHO, 2007)

O TFDF avalia a discriminação fonêmica em crianças brasileiras falantes de PB. Este instrumento observa aspectos quantitativos e qualitativos durante a tarefa de discriminar as diferenças entre os fonemas desta língua. $\mathrm{O}$ teste foi organizado a partir de pares mínimos do PB, seguindo o formato do Teste de Percepção de Boston (The Boston University Speech Sound Discrimination Test) de Pronovost e Dombleton (1953). A criança ouve um par de palavras e em uma ficha deve escolher duas figuras que representam as palavras que ouviu, entre três pares de figuras que representam as palavras eliciadas. Há 4 itens de demonstração e 40 de avaliação.

\section{Teste de Figuras para Discriminação Fonêmica na Libras}

(Equipe do Projeto Desenvolvimento Bilíngue Bimodal)

Para a Libras, foi elaborado um teste para avaliar a discriminação fonêmica, com base em pares mínimos da Libras seguindo a organização do teste elaborado por Carvalho (2007). Foram selecionados pares mínimos a serem identificados por figuras. Os pares mínimos diferem quanto à configuração de mão, ao movimento, à locação, ou à orientação da mão. O teste apresenta instrução filmada. Há um item de demonstração e 27 de avaliação.

\section{Narrativa do Carl em Libras}

\section{Narrativa do Carl em PB}

(Equipe do Projeto Desenvolvimento Bilíngue Bimodal)

No teste de produção de narrativas com base em histórias do Cachorro Carl, o experimentador deve motivar a criança a conversar com ele sobre a história e sobre outras coisas que podem ser tópico da conversa a partir das histórias. O objetivo é ter uma amostra da conversação e narrativa da criança em Português e em Libras. São propostas diferentes histórias com o mesmo personagem principal, o cachorro Carl. 
19. Teste de eliciação de interrogativas em Libras

20. Teste de eliciação de interrogativas no PB

(Equipe do Projeto Desenvolvimento Bilíngue Bimodal)

Este teste promove a produção de perguntas elaboradas pelas crianças a um participante (pessoa que será o personagem 'gato'), após a apresentação de uma situação apresentada pelo/a examinador/a que necessita a opinião do personagem. Para a apresentação desta situação a examinadora utilizará bonecos que representam personagens de desenhos infantis para então solicitar à criança que elabore uma pergunta relacionada à situação, para o personagem 'gato', como pode ser observado na situação abaixo que avalia como a criança usa o sujeito a longa distância:

Bonecos: Olivia, Ian, Mãe, Pai

Situação apresentada pelo(a) examinador(a) à criança:

Jantar terminou e alguém precisa lavar a louça. Eu penso que o Ian poderia lavar a louça. E você? Acha que quem poderia lavar a louça?

$O k$, você e eu pensamos que o Ian poderia lavar a louça. Pergunta para o gato quem ele pensa. Agora é hora de ir para cama. Alguém precisa ir tomar banho. Eu quero que a Olivia vá tomar o banho. O que você quer?

Ok, você e eu queremos que Olivia vá tomar banho. Pergunta ao gato quem ele quer.

Neste teste é proposto que a criança elabore interrogativas com: objeto-WH, uma oração; sujeito-WH, uma oração; adjunto- $\mathrm{WH}$, uma oração; sujeito- $\mathrm{WH}$, longa distância; objeto-WH, longa distância e adjunto-WH, longa distância.

\section{Amostra da interação entre pai/mãe-criança}

(Equipe do Projeto Desenvolvimento Bilíngue Bimodal)

Para orientar a coleta da amostra de interação entre a criança e o familiar são utilizadas figuras temáticas. O objetivo é ter uma amostra do input que a criança recebe no dia-adia. As fichas possuem os seguintes temas: 'supermercado', 'feira', 'festa de aniversário', 'parque de diversōes', 'zoológico', 'piquenique' e 'sala de aula'. 
22. Inventário Mac Arthur de Desenvolvimento Comunicativo: Primeiras palavras e gestos - Proposta em Português Brasileiro elaborada por Elizabeth Reis Teixeira e Cláudia Tereza S. da Silva (2003)

A proposta do Inventário Mac Arthur em Português Brasileiro, elaborada por Teixeira e Silva, investiga aspectos relacionados à compreensão e produção da linguagem em crianças de 8 a 16 meses de idade e será preenchida pelos pais com orientação de um profissional da equipe de pesquisa.

\section{Kendall}

(FRENCH, 1999, adaptado para Libras por QUADROS, 2004)

O protocolo Kendall (FRENCH, 1999) foi desenvolvido para acompanhar o desenvolvimento das habilidades comunicativas na ASL e foi adaptado para Libras (QUADROS, 2004). Este protocolo está organizado por níveis que foram estabelecidos conforme o aumento do grau de complexidade das habilidades comunicativas. Para cada nível, há uma ficha contendo as habilidades comunicativas que devem ser observadas e marcadas até o nível que a criança consegue atingir.

\section{Teste de Avaliação Intelectual’: \\ Leiter International Performance Scale Revised (ROID \& MILLER, 1997)}

Este é um teste completamente não verbal e, portanto, exclui a questão da linguagem para a sua execução. Desta forma, temos uma avaliação que pode evidenciar questōes relativas ao desenvolvimento intelectual da criança que não estejam relacionadas com a linguagem. Na presente pesquisa foram utilizados quatro sub-testes: "Figure Ground" e "Form Completion" que enfocam o raciocínio; "Sequencial Order" e "Repeated Patterns", que enfocam a visualização espacial. Os erros e os acertos são registrados em formulário próprio para posteriormente ser feita a conversão dos escores e calculado o QI da criança. Esse teste avalia crianças/jovens de 2 a 20 anos.

${ }^{6}$ Foram utilizados dois tipos de protocolo de avaliação de desenvolvimento linguístico: o Inventário Mac Arthur de Desenvolvimento Comunicativo (item 22) e o protocolo Kendall (item 23). Os protocolos serviram para situar o contexto de aquisição de cada criança.

${ }^{7} \mathrm{Na}$ bateria de testes foi incluída a avaliação do QI, pois investigamos o processo de aquisição da linguagem por crianças sem comprometimentos cognitivos. 


\section{Análise parcial dos testes realizados}

Nesta seção, apresentaremos uma amostra dos resultados encontrados em alguns dos testes já analisados. $\mathrm{O}$ recorte que será apresentado aqui é referente a aspectos da fonologia das línguas de sinais e do português. Os demais testes foram aplicados e os dados foram coletados, mas ainda se encontram em fase de análise. Consideramos importante apresentar anteriormente o conjunto inteiro dos testes, que constituem vários aspectos da linguagem dessas crianças, pois há uma carência em relação a instrumentos de avaliação de linguagem para crianças surdas e crianças bilíngues bimodais na literatura da área. Os instrumentos existentes estão disponíveis para a avaliação da língua falada pela criança, mas não da língua sinalizada por ela.

Assim, o propósito do presente artigo foi apresentar os testes desenvolvidos pela equipe de pesquisadores do Projeto Desenvolvimento Bilíngue Bimodal e compartilhar os resultados dos testes que já foram analisados. Esse conjunto configura o mosaico da linguagem dessas crianças, que vai sendo composto aos poucos para ser socializado com a comunidade científica.

A aplicação dos testes mostrou-se bem sucedida, compondo o mosaico da linguagem com dados consistentes que serão analisados ao longo dos anos subsequentes às coletas. Os dados coletados fazem parte do Banco de Dados do Núcleo de Aquisição de Língua de Sinais da Universidade Federal de Santa Catarina e podem ser acessados por outros pesquisadores mediante permissão específica para a realização de pesquisas, com a devida autorização explícita dos pais das crianças pesquisadas.

\subsection{Testes de pseudopalavras e pseudossinais}

O estudo sobre memória fonológica em crianças ouvintes bilíngues bimodais e crianças com IC comparou o desempenho de 5 crianças bilíngues bimodais ouvintes (filhas de pais surdos) e 5 crianças surdas com IC (filhas de pais surdos e de pais ouvintes), com diferentes contextos de acesso à Libras, em tarefas que envolvem memória fonológica (QUADROS, CRUZ \& PIZZIO, 2012). Além disso, foram incluídos dois grupos de controle, formados por 3 crianças surdas usuárias de Libras e 3 adultos bilíngues bimodais ouvintes. A avaliação da memória fonológica ocorreu por meio da aplicação de um teste de pseudopalavras (SANTOS \& BUENO, 2003) e um teste de pseudossinais (Equipe do Projeto Desenvolvimento Bilíngue Bimodal). Na análise dos resultados, com relação ao desempenho entre 
os dois grupos testados, foi constatado que o grupo de crianças bilíngues bimodais ouvintes apresentou desempenho superior, nos dois testes. No entanto, ao ser analisado o desempenho da criança surda com IC, filha de pais surdos, que possui acesso irrestrito à Libras e comparado com o das crianças surdas com IC, que possuem acesso restrito à Libras, foi constatado que o seu desempenho foi semelhante ao do grupo de crianças bilíngues bimodais ouvintes. As crianças surdas com IC com acesso restrito à Libras e, portanto, com acesso maior ao $\mathrm{PB}$ apresentaram escores mais baixos nas tarefas, principalmente do teste em $\mathrm{PB}$. Os resultados sugerem que as crianças surdas com IC em processo de aquisição da linguagem podem se beneficiar com o acesso irrestrito à Libras, atingindo inclusive desempenho semelhante a de crianças bilíngues bimodais ouvintes.

Porém, ao fazer uma análise mais detalhada dos dois testes, os dados indicam, de modo geral, uma dissociação entre os dois sistemas fonológicos das línguas avaliadas. As crianças apresentam desempenhos diferentes quando realizam os testes na Libras ou no PB. Esses sistemas utilizam canais articulatórios diferentes, ou seja, as mãos e a visão no caso da Libras e a audição e a voz, no caso do PB. As modalidades das línguas são diferentes e isso parece ter implicações nos resultados observados, quando comparamos crianças ouvintes bilíngues bimodais com crianças surdas com IC. Alguns efeitos parecem também ser identificados dentro dos próprios grupos avaliados, pois o fato de um grupo poder ouvir naturalmente o $\mathrm{PB}$ e ver a Libras e o outro ouvir o PB utilizando um dispositivo auditivo e ver a Libras pode indicar efeitos de modalidade no processamento dessas línguas. Os resultados evidenciam que as crianças Kodas apresentam os sistemas fonológicos específicos de cada língua de forma apropriada. Elas conseguem identificar os padrôes fonológicos presentes em suas línguas e reproduzi-los, na repetição. No entanto, há uma pequena diferença entre o desempenho no teste de pseudopalavras e pseudossinais. Talvez essa diferença tenha relação com as questóes envolvendo a diferença entre a modalidade das línguas. Como estas crianças ouvem o PB sem nenhum tipo de restrição e sua atenção compete entre a audição e a visão, há implicações na atenção aos sinais na hora de visualizá-los e, então, reproduzi-los.

Por outro lado, no caso das crianças surdas com IC, principalmente às com acesso restrito à Libras, há grandes dificuldades na produção das pseudopalavras e algumas dificuldades na produção dos sinais, durante a repetição. O desempenho das crianças surdas com IC é melhor na Libras 
do que no $\mathrm{PB}$, mesmo considerando que elas possam estar mais expostas ao $\mathrm{PB}$ do que à Libras. Essa diferença também pode estar relacionada com a diferença na modalidade das línguas. As crianças surdas com IC, apesar de passarem a ouvir, continuam sendo surdas, ou seja, elas continuam favorecendo o canal visual em relação ao canal auditivo. Os resultados sugerem que estas crianças tiveram mais possibilidades de processarem as informações linguísticas, em nível fonológico, por meio da visão do que por meio da audição (sem leitura orofacial). Assim, elas, mesmo tendo restrições de acesso à Libras, conseguem apresentar melhor desempenho na Libras, uma língua que está acessível visualmente, portanto, uma língua mais fácil, que oferece acesso completo. Elas aproveitaram o input que tiveram, mesmo sendo não muito convencional, para ativar a linguagem.

Os resultados indicam que crianças ouvintes bilíngues bimodais apresentam um desempenho adequado em tarefas que avaliam a memória fonológica na Libras e no PB. Além disso, parece que crianças surdas com acesso irrestrito à Libras que recebem implantes cocleares precocemente e que realizam o acompanhamento fonoaudiológico, podem apresentar desempenho semelhante às crianças ouvintes bilíngues bimodais. Dessa forma, a aquisição precoce da língua de sinais pode ser um importante fator a ser considerado no desenvolvimento linguístico de crianças surdas que realizaram a cirurgia para a colocação do IC. Iniciar o processo de aquisição da língua oral com a vantagem de não apresentar atraso no processo de aquisição da linguagem por ter iniciado a aquisição de determinada língua de sinais (língua natural em uma modalidade que possibilita à criança surda acesso completo às informaçóes linguísticas) pode contribuir para o desenvolvimento geral da criança e para o sucesso na aquisição da língua oral.

O estudo binacional que comparou os dados de crianças Kodas e crianças surdas com IC, brasileiras e americanas, nos dois pares de línguas: Libras-PB e ASL-Inglês (CRUZ et al. 2014) apresentou resultados semelhantes aos encontrados em Quadros, Cruz e Pizzio (2012). As crianças ouvintes bilíngues bimodais e surdas com IC com acesso à língua de sinais precocemente alcançaram acima de $90 \%$ de acerto na produção do número de sílabas e acento. A acurácia total de crianças surdas com IC brasileiras e americanas ficou abaixo das crianças ouvintes bilíngues bimodais. Os dados quanto ao número de sílabas e acento das crianças surdas com IC americanas foram semelhantes aos dados da criança surda com IC brasileira, filha de pais surdos (com acesso irrestrito à Libras), corroborando que a aquisição 
precoce da língua de sinais pode contribuir para o desenvolvimento geral da criança e da aquisição da língua oral, conforme mencionado anteriormente.

\subsection{Avaliação fonológica}

A aquisição fonológica do PB por crianças ouvintes bilíngues bimodais e crianças surdas com IC com diferentes acessos à Libras foi investigada recentemente por Cruz e Finger (2013). Participaram desse estudo 24 crianças ouvintes bilíngues bimodais e 6 crianças surdas com IC (6 com acesso restrito e uma com acesso irrestrito à Libras). Para essa investigação foi aplicada a Parte A, Prova de Nomeação, do ABFW - Teste de Linguagem Infantil (ANDRADE et al., 2004). Os resultados revelaram que as crianças ouvintes bilíngues bimodais e a criança surda com IC com acesso irrestrito à Libras apresentaram um processo de aquisição fonológica esperada e análogo às crianças monolíngues. Por outro lado, a aquisição fonológica por crianças com IC com acesso restrito à Libras está sendo estabelecida de forma diversificada. Essas crianças apresentaram variação no desempenho, sendo que a maioria está em processo de aquisição da fonologia do PB em etapas iniciais. As variáveis envolvidas, idade, tempo de exposição à Libras e ao PB e idade em que o processador de fala do IC foi ligado podem ter influenciado de alguma forma no desempenho dessas crianças. No entanto, a aquisição da língua de sinais pode ter sido uma vantagem para a criança surda que teve acesso à Libras desde o nascimento e que recebeu o IC precocemente, pois iniciou a aquisição do $\mathrm{PB}$ quando o processo de aquisição da linguagem, na língua de sinais, estava em desenvolvimento.

Um estudo binacional desenvolvido com crianças brasileiras e americanas investigou a aquisição da fonologia em dois pares de línguas de diferentes modalidades, Libras-PB e ASL-Inglês (CRUZ et al., 2014) e confirmou os achados do estudo citado anteriormente em relação à língua oral, apresentando interessantes resultados em relação à aquisição bimodal. Os participantes foram distribuídos em três grupos, a saber: crianças ouvintes bilíngues bimodais ( 24 brasileiras e 20 americanas), crianças surdas com IC com acesso irrestrito à Libras ( 1 brasileira e 4 americanas) e crianças surdas com IC com acesso restrito à Libras ( 5 brasileiras). Os testes utilizados em PB e Inglês foram: Parte A, Prova de Nomeação, do ABFW - Teste de Linguagem Infantil (ANDRADE et al., 2004) e Goldman-Fristoe Test of Articulation 2; Pearson, e os testes utilizados em Libras e ASL foram propostos por Cruz (2008), sendo que traduzido para ASL. 
Os resultados mostraram que crianças ouvintes bilíngues bimodais estão adquirindo o PB e o Inglês de forma esperada (normal) e análoga às crianças monolíngues, assim como a criança surda brasileira e as crianças surdas americanas com IC, que possuem acesso irrestrito à língua de sinais. As crianças surdas com IC brasileiras com acesso restrito à Libras apresentaram desvantagem em relação aos outros grupos. Foi observada variação individual, sendo que a maioria está em processo inicial de aquisição da fonologia. Em relação aos resultados dos testes em Libras e ASL a maioria das crianças ouvintes bilíngues bimodais produziram sinais sem estratégias de reparo, assim como as crianças surdas com IC com acesso irrestrito à Libras. Surpreendentemente, as crianças surdas com IC com acesso restrito à Libras apresentaram desempenho próximo às outras crianças participantes e melhor desempenho no teste em Libras do que em PB, sugerindo que, mesmo ocorrendo uma restrição no acesso à Libras, o processamento das informaçôes linguísticas por surdos ocorre de forma mais efetiva por meio do canal visual. Esse estudo conclui que a aquisição da fonologia por crianças ouvintes bilíngues bimodais e surdas com IC pode ocorrer sem prejuízos na língua oral e na língua de sinais e sugere que crianças surdas com acesso irrestrito à Libras podem ter alguma vantagem no processo de aquisição da fonologia da língua oral, pois no momento em que foram expostas ao PB e ao Inglês, possivelmente não apresentavam atrasos no processo de aquisição da linguagem.

\subsection{Teste de discriminação fonêmica}

A habilidade de discriminação fonêmica do PB e da Libras em crianças e adultos ouvintes bilíngues bimodais (filhos de pais surdos) e em crianças surdas com IC, filhas de pais surdos ou de pais ouvintes, com acesso restrito e irrestrito à Libras, foi investigada por Cruz, Pizzio e Quadros (2015). Participaram desse estudo 6 crianças com IC, com idade entre 5-8 anos ( 5 com acesso restrito à Libras e uma com acesso irrestrito à Libras), e um total de 23 crianças Kodas com idade entre 4-8 anos. Vinte e três crianças realizaram o teste em PB e 14 em Libras. Além disso, foi incluído um grupo controle composto por 6 adultos ouvintes bilíngues bimodais (Kodas). Os testes aplicados foram: Teste de Figuras para Discriminação Fonêmica-TFDF (SANTOS-CARVALHO, 2007) e o Teste de Discriminação FonêmicaLibras, elaborado pela equipe do Projeto Desenvolvimento Bilíngue Bimodal, que seguiu a organização do teste elaborado por Santos-Carvalho 
(2007). Os resultados deste estudo mostram que o desenvolvimento da habilidade de discriminação fonêmica do PB e da Libras em crianças Kodas está ocorrendo de forma esperada/normal. Entre as crianças surdas com IC o desempenho foi melhor em Libras do que em PB, independentemente do tipo de acesso: restrito ou irrestrito. A habilidade de discriminação fonêmica da criança surda com acesso irrestrito à Libras, foi superior às outras crianças surdas em ambos os testes (atingiu escores semelhantes às crianças Kodas no teste em PB e igualou-se aos adultos Kodas no teste em Libras). A exposição à Libras desde o nascimento, portanto, não traz prejuízos para a habilidade de discriminar fonemas. A oportunidade de crianças surdas iniciarem a aquisição da linguagem desde o nascimento ou muito precocemente (sem atrasos) pode ser um dos fatores que favoreça o processo de aquisição de outra língua independentemente da modalidade que se apresente.

\section{Considerações finais}

O presente trabalho teve como objetivo mostrar como está sendo investigado o desenvolvimento bilíngue bimodal de crianças surdas com IC e crianças ouvintes, filhas de pais surdos, expostas a duas línguas de modalidades diferentes, a Libras e o PB. Foram apresentados os testes realizados e detalhada a forma de aplicação dos mesmos, bem como os resultados de alguns testes aplicados.

Os estudos apresentados mostram que o processo de aquisição bilíngue bimodal por crianças Kodas e por crianças surdas com IC com acesso irrestrito à Libras está ocorrendo de forma análoga ou próxima do esperado (normal) no PB e na Libras. Além disso, o desempenho idêntico ou semelhante entre crianças Kodas e crianças monolíngues nos testes de fonologia (avaliação fonológica, teste de pseudopalavras e de discriminação fonêmica) do $\mathrm{PB}$, permite-nos concluir que a aquisição bilíngue bimodal pode ocorrer de forma esperada, e que as diferenças entre as modalidades de línguas não trazem prejuízos para a aquisição de uma língua oral e de uma língua de sinais, mesmo quando ambas estão sendo adquiridas simultaneamente.

Considerando os achados dos estudos relacionados às crianças surdas com IC, desenvolvidos no Projeto Desenvolvimento Bilíngue Bimodal, até o momento, a possibilidade de acesso irrestrito a uma língua de sinais desde o nascimento pode ter sido um dos fatores que contribuiu para que a aquisição da língua oral ocorresse de forma esperada ou próxima ao esperado, pois a 
aquisição da língua oral iniciou quando o processo de aquisição da linguagem já estava em andamento. Nesse caso, as crianças já tinham uma experiência linguística rica e muitas aprendizagens que decorrem dela e possivelmente melhores condições de aprendizagem de outra língua. $\mathrm{O}$ mesmo não ocorreu com as crianças com acesso restrito à Libras, pois iniciaram a aquisição da língua oral com menos tempo de exposição e menor experiência linguística. Ainda sobre os achados dos estudos relacionados às crianças surdas com IC, as crianças surdas com IC e com acesso restrito à Libras, mesmo tendo mais acesso à língua oral, em geral apresentaram melhor desempenho nos testes em Libras. Esse resultado surpreendente sugere que a experiência linguística visual para essas crianças permanece ativada e é um caminho "natural" para a aquisição da linguagem de forma rápida e efetiva.

Acreditamos que os resultados desse trabalho possam contribuir para que mais estudos sobre aquisição bilíngue bimodal sejam desenvolvidos com crianças ouvintes ou surdas e para que as questóes relacionadas a esse processo, em fase inicial de investigação, sejam aprofundadas e esclarecidas.

\section{Referências}

AlvareZ, A.; CARVAlHO, I.; CAETANO, A. 2004. Perfil de habilidades fonológicas, São Paulo: Via Lettera.

ANDRADE, C.; BEFI-LOPES, D.; FERNANDES, F.; WERTZNER, H. 2004 ( $2^{\mathrm{a}}$ ed.). Teste de linguagem Infantil nas Áreas de Fonologia, Vocabulário, Fluência e Pragmática. Barueri: Pró-Fono.

CHEN PICHLER, D., HOCHGESANG, J., LILLO-MARTIN, D.; QUADROS, $\mathrm{R}$. Conventions for sign and speech transcription in child bimodal bilingual corpora, Language, Interaction and Acquisition, v.1, n.1, p.11-40, 2010. Disponível em: http://www.ncbi.nlm.nih.gov/pmc/articles/PMC3102315/pdf/nihms273872. pdf. Acesso em: 05 ago. 2015.

CRAIN, S.; MCKEE, C. Acquisition of Structural Restrictions on Anaphora. In: BERMAN , S., CHOE J.-W.; MCDONOUGH, J. (eds.), Proceedings of the North Eastern Linguistic Society. GLSA, University of Massachusetts, Amherst. 1986. 16, p. $94-110$

CRAIN, S.; THORNTON, R. Investigations in Universal Grammar: A Guide to Experiments on the Acquisition of Syntax and Semantics, 1998. Cambridge, MA, MIT Press. 
CRUZ, C. Proposta de instrumento de avaliação da consciência fonológica, parâmetro configuração de mão, para crianças surdas utentes da Lingua de Sinais Brasileira. Dissertação. 2008. 196 f. (Mestrado em Letras-Linguística Aplicada). Programa de Pós-Graduação em Letras, Pontifícia Universidade Católica do Rio Grande do Sul, Rio Grande do Sul, 2008. Disponível em: http://tede.pucrs.br/tde_arquivos/16/ TDE-2008-03-28T065530Z-1103/Publico/399739.pdf. Acesso em: 06 ago. 2015. CRUZ, C.; FINGER, I. Aquisição fonológica do português brasileiro por crianças ouvintes bilíngues bimodais e surdas usuárias de implante coclear, Letras de Hoje, v.48, n. 3, p.389- 398, 2013. Disponível em: http://revistaseletronicas.pucrs.br/ ojs/index.php/fale/article/view/12621/9928. Acesso em: 06 ago. 2015.

CRUZ, C.; KOZAK, L.; PIZZIO, A.; QUADROS, R.; CHEN PICHLER, D. Phonological memory and phonological acquisition in bimodal bilingual children. In: ORMAN, W.; VALLEAU , M. J. (eds.), Proceedings of the 38th Annual Boston University Conference on Language Development. Somerville, MA: Cascadilla Press. 2014. p.103-115.

CRUZ, C.; PIZZIO, A.; QUADROS, R. Avaliação da discriminação fonêmica do português brasileiro e da Língua de Sinais Brasileira em crianças ouvintes bilíngues bimodais e em crianças surdas usuárias de implante coclear. Revista da ABRALIN,v. 14, n.1,jan./jun., p. 337-360, 2015. Disponível em: http://ojs.c3sl.ufpr.br/ojs/ index.php/abralin/article/view/42824/25976. Acesso em: 22 jan. 2016.

DAVIDSON, K.; LILLO-MARTIN, D.; CHEN PICHLER, D. Spoken English Language Development in Native Signing Children with Cochlear Implants. Journal of Deaf Studies and Deaf Education, v.19, n.2, p-238-250, 2013. Disponível em: http://jdsde.oxfordjournals.org/content/19/2/238.long . Acesso em: 05 ago. 2015.

EMMOREY, K.; BORINSTEIN, H.; THOMPSON, R. \& GOLLAN, T. Bimodal bilingualism. Bilingualism: Language and Cognition, v.11, n.1, p. 43-61, 2008. Disponível em: http://www.ncbi.nlm.nih.gov/pmc/articles/PMC2600850/pdf/ nihms-49018.pdf. Acesso em: 05 ago. 2015.

FORTUNATO, C.; BEVILACQUA, M.; COSTA, M. Análise comparativa da linguagem oral de crianças ouvintes e surdas usuárias de implante coclear, Rev. CEFAC, v.11, n.4, p. 662-672, 2009. Disponível em: http://www.scielo.br/scielo. php?script=sci_arttext\&pid=S1516-18462009000800015. Acesso em: 05 ago. 2015.

FRENCH, M. A Developmental Approach to DeafChildren's Literacy. Gallaudet University. Pre-College National Mission Programs. Washington, DC. 1999.

GEERS, A. Speech, Language, and Reading Skills After Early Cochlear Implantation. Arch Otolaryngol Head Neck Surg, v.130, p. 634-638, 2004. 
GOLDMAN, R., Fristoe, M, 2000. Goldman-Fristoe Test of Articulation 2. San Antonio, TX: Pearson.

LILLO-MARTIN, D.; QUADROS, R.; KOULIDOBROVA, E.; CHEN PICHLER, D. Bimodal bilingual cross-language influence in unexpected domains. In: COSTA, J.; CASTRO, A.; LOBO, M.; PRATAS, F. (eds.), Language Acquisition and Development: Proceedings of GALA 2009, Newcastle upon Tyne: Cambridge Scholars Press, 2010. p. 264-275.

PADOVANI, C.; TEIXEIRA, E. Do balbucio à fala: reflexões sobre a importância das atividades lingüísticas iniciais e o desenvolvimento da linguagem oral em crianças com deficiência auditiva, Distúrbios da Comunicação, v.17, n.1, p. 45-54, 2005. Disponível em: http://revistas.pucsp.br/index.php/dic/article/ view/11681/8408. Acesso em: 05 ago. 2015.

PRONOVOST, W.; DUMBLETON, C. A picture-type speech sound discrimination test. Journal of Speech and Hearing Disorders, v. 18, p.258-266, 1953. QUADROS, R. Avaliação da língua de sinais em crianças surdas na escola. Letras de Hoje, Porto Alegre, v. 39, n.3, p.297-309, 2004. Disponível em: http:// revistaseletronicas.pucrs.br/ojs/index.php/fale/article/view/13922/9235. Acesso em: 06 ago. 2015.

QUADROS, R.; CRUZ, C. 2011. 159p. Linguas de Sinais: instrumentos de avaliação, Porto Alegre, Artmed.

QUADROS, R.; CRUZ, C.; PIZZIO, A. Memória fonológica em crianças bilíngues bimodais e crianças com implante coclear, ReVEL, v. 10, n.19, 2012. Disponível em: http://www.revel.inf.br/files/0bb2012c5e0acde671a087e69739aab9.pdf Acesso em: 06 ago. 2015.

QUADROS, R.; LILLO-MARTIN, D.; CHEN PICHLER, D. Bilinguísmo e Bimodalismo Desenvolvimento Bilíngue Intermodal. 2010. In: IX Congresso Internacional e XV Seminário Nacional do INES. Anais do Congresso do INES: O lugar do Conhecimento: identidade sujeito e subjetividade, Rio de Janeiro, Editora do INES, 2010. p.146-150.

ROID, G.; MILLER, L, 1997. Leiter International Performance Scale - Revised. In: Wood Dale, IL:Stoelting Co.

SANTOS-CARVALHO, B. Teste de figuras para discriminação fonêmica: proposta e aplicação. 2007. 149 fls. Dissertação (Mestrado em Distúrbios da Comunicação Humana). Programa de Pós-Graduação em Distúrbios da Comunicação, Universidade Federal de Santa Maria, Rio Grande do Sul, 2007. Disponível em: http://cascavel.cpd.ufsm.br/tede/tde_busca/arquivo.php?codArquivo=1383. Acesso em: 05 ago. 2015. 
SANTOS, F.; BUENO, O. Validation of the Brazilian Children's Test of Pseudoword Repetition in Portuguese speakers aged 4 to 10 years. In: Brazilian Journal of Medical and Biological Research, v.36, p.1533-1547, 2003. Disponível em: http://www.scielo.br/scielo.php?pid=S0100-879X2003001100012\&script=sci_ arttext. Acesso em: 05 ago. 2015.

STUCHI, R.; NASCIMENTO, L.; BEVILACQUA, M.; NETO, R. Linguagem oral de crianças com cinco anos de uso do implante coclear, Pró-Fono R. Atual. Cient.,v.19, n.2, p.167-176, 2007. Disponível em: http://www.scielo.br/scielo. php?script=sci_arttext\&pid=S0104-56872007000200005. Acesso em: 05 ago. 2015.

TEIXEIRA, E.; SILVA, C. Adaptação para o português brasileiro do MacArthur Communicative Inventories. CDI: Words and Gestures, 2003.

TOOHEY, E. Phonological development in hearing children of deaf parents. 2010. Honors Scholar Theses. 40 fls. University of Connecticut, Storrs, 2010. Disponível em: http://digitalcommons.uconn.edu/cgi/viewcontent. cgi?article $=1150 \&$ context=srhonors_theses. Acesso em: 05 ago. 2015 . WILLIAMS, K, 1997. Expressive vocabulary test. San Antonio, TX: Pearson. ZIMMERMAN, I.; STEINER, V.; POND, R, 2002. Preschool Language Scale, Fourth Edition (PLS-4), San Antonio, TX: Harcourt Assessment.

Data de submissão: 19/08/2015. Data de aprovação: 21/01/2016 